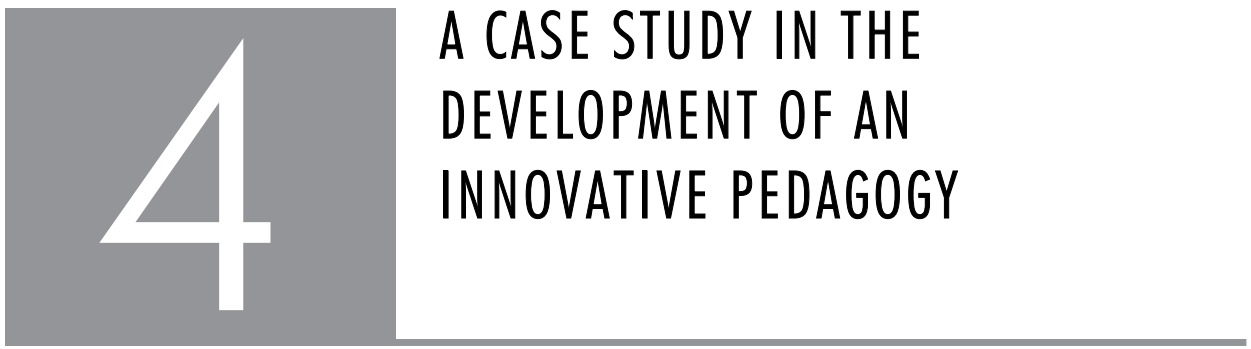

\title{
Laurie Woollacott
}

\section{INTRODUCTION}

The focus of this chapter is the Scholarship of Teaching and Learning (SoTL) at the 'coalface' of teaching undergraduate students. It will describe the design and implementation of an innovative, active-learning technique termed 'Mediated-Interaction Groups' or MIGs. The development of this technique is an interesting case study of how reflective practice in addressing teaching and learning challenges led to a new kind of intervention, which then evolved further into a more settled pedagogy through a process that involved engagement with the literature, evaluation of the implemented pedagogy, and contact with the wider community of higher education practice.

The chapter is divided into five sections. The first presents, with little preamble, the MIG pedagogy that has been developed and explains briefly its objective and underlying rationale. The second section outlines the context in which the pedagogy was developed and briefly reviews relevant literature. The third section explains how the pedagogy evolved, and the fourth how it has been evaluated - how students experienced the MIG sessions and how these sessions impacted their learning. The fifth section is a reflection on the MIG methodology and its development from the point of view of SoTL and its transformative potential. The section also includes a more personal reflection on how the development of the innovation and my attempts to dissemination awareness of the methodology have impacted me as a teacher and researcher. 


\section{THE SCHOLARSHIP OF TEACHING AND LEARNING IN HIGHER EDUCATION}

\section{THE MIG METHODOLOGY}

The objective of the MIG methodology is to enhance student learning through the agency of mediation processes that operate in a group discussion that is strongly guided. It is based on a well-known finding that significant learning benefits accrue when a student articulates his or her ideas and thinking in an interactive learning environment (Goos, Galbraith \& Renshaw 2002). The methodology was developed for first-year students in an engineering programme as an intervention to improve their understanding of important concepts which they found difficult to grasp.

The MIG format is summarised graphically in Figure 4.1. It consists of four 'participants', at least ten 'observers' and a strong mediator, all seated around a table as shown. The visible activity occurs in the 'circle of interaction' and consists of the participants being drawn by the mediator into a discussion around topics relevant to the course material. Each MIG session is of short duration - between 30 and 40 minutes. Resources to help facilitate the discussion are available in the form of a chalkboard and a table for any materials or equipment that may be needed.

Observers do not participate actively in the discussion except on rare occasions at the mediator's discretion. However, from one MIG session to the next, students rotate between being observers and participants so that over a period of time every student has the opportunity to engage as a participant several times during a semester.

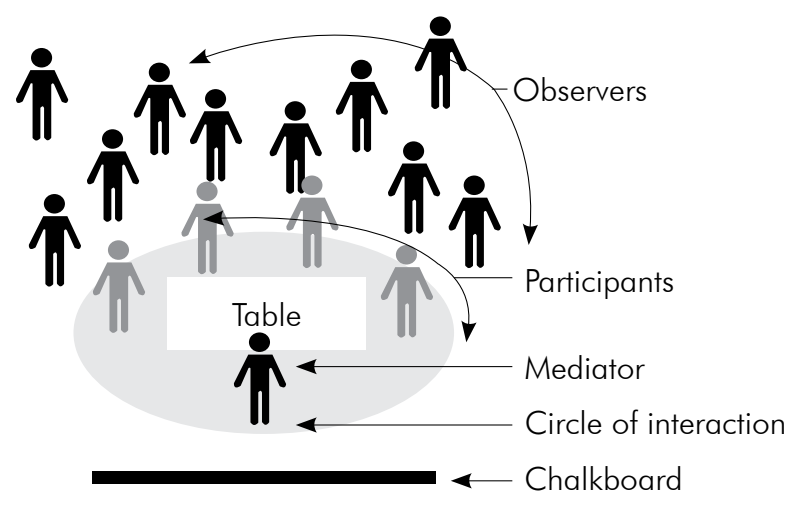

FIGURE 4.1 The MIG format

\section{Mediation and facilitation in a MIG session}

The mediator has a double role. The first is to facilitate the session in a way that creates and maintains healthy group dynamics and an environment that is conducive to learning. Although this is a common responsibility for any instructor or mediator 
in an educational situation (Feverstein \& Feverstein 1991), it is particularly important in a MIG session because participants are put 'on the spot' in a way which can lead to embarrassment and awkward situations if the mediator is not alert. The success of the format depends on gaining the trust of the students so that the MIG environment, though pressured, is seen by them to be 'safe'. Students need to feel that it is safe to be wrong and to risk making erroneous interpretations or judgements. To this end, I have found that the interactions need to be kept light, respectful, and sprinkled with humour, so that the ambiance which is maintained lies somewhere between a conversation, a technical discussion and a 'playful interrogation'. I have found that this kind of informal atmosphere does not impede the MIG objectives of facilitating conceptual mastery and deepened understanding if this objective has been made clear to the students during their initial induction into the MIG format.

The second role of the mediator is crucial: the mediation of learning. The intention is to lift the interactions from the level of a facilitated discussion to one where the interactions promote learning and conceptual development as much as possible. This involves more than ensuring that the discussion remains focused and flowing. It requires paying attention to the understandings and perceptions which the MIG participants express and being involved in the discussion in ways that advance, develop or, if necessary, correct the students' perceptions. At times, this will mean acting as 'the more learned other' in learner-mediator interactions - asking direct questions, giving comments or 'nudging' the focus of the discussion so that the participants engage with their conceptions differently and more deeply. At other times, it will mean fostering learner-peer and learner-self mediation - encouraging peer discussion and individual explanations, and, if appropriate, drawing these out by calling for elaboration or suggesting a different perspective. Table 4.1 summarises some of the key principles in this kind of mediation and Laing (2007) and Xun (2004) provide some useful tips in facilitating discussions that are effective in promoting learning. 


\section{THE SCHOLARSHIP OF TEACHING AND LEARNING IN HIGHER EDUCATION}

TABLE 4.1 Feverstein's twelve principles of mediation

\begin{tabular}{|c|c|}
\hline PRINCIPLE & The mediator should. \\
\hline $\begin{array}{l}\text { Intentionality and } \\
\text { reciprocity }\end{array}$ & $\begin{array}{l}\text { Focus learner's attention to enable receptivity to learning. Provide prompts } \\
\text { to ascertain level of understanding. Encourage learner to respond. }\end{array}$ \\
\hline Meaning & $\begin{array}{l}\text { Make the activity meaningful to the learner and interact with him/her to } \\
\text { overcome any resistance that might be present. }\end{array}$ \\
\hline Transcendence & $\begin{array}{l}\text { Widen the learner's awareness by promoting abstract thinking, and getting } \\
\text { him/her to look for generalisations and connections with other things. }\end{array}$ \\
\hline $\begin{array}{l}\text { Regulation of } \\
\text { behaviour }\end{array}$ & $\begin{array}{l}\text { Make learners aware of their behaviour in relation to the intended purpose } \\
\text { of the session in order to facilitate any adjustment that may be needed. }\end{array}$ \\
\hline $\begin{array}{l}\text { Feelings of } \\
\text { competence }\end{array}$ & Instil in the learner a positive sense of belief in his/her ability. \\
\hline Sharing behaviour & Foster mutual cooperation and empathetic interaction. \\
\hline Individuation & $\begin{array}{l}\text { Convey acceptance and appreciation of the learner and awareness of his/ } \\
\text { her uniqueness. }\end{array}$ \\
\hline Goal planning & $\begin{array}{l}\text { Help the learner to identify goals to strive for and how to achieve them. } \\
\text { Encourage perseverance and commitment. }\end{array}$ \\
\hline Challenge & $\begin{array}{l}\text { Encourage the leaner to accept the challenge of responding to the } \\
\text { unknown and bolster the learner' self-belief in this regard. }\end{array}$ \\
\hline Self-change & $\begin{array}{l}\text { Foster in the learner a belief in the possibility of self-change and an } \\
\text { expectation of personal growth. }\end{array}$ \\
\hline $\begin{array}{l}\text { Search for optimistic } \\
\text { alternatives }\end{array}$ & Develop the learner's proactivity and optimism for self-directed change. \\
\hline $\begin{array}{l}\text { Feeling of } \\
\text { belonging }\end{array}$ & $\begin{array}{l}\text { Promote the awareness of the importance of interdependence and the } \\
\text { necessity for cooperation. }\end{array}$ \\
\hline
\end{tabular}

Source: Feverstein (1979), Feverstein \& Feverstein (1991), as adapted from Seabi (2004)

The following extracts illustrate typical interactions in a MIG session. (The extracts derive from MIG sessions in 2007 that were recorded and transcribed with permission from students after university ethical clearance had been obtained.)

The first extract illustrates how each student in turn is drawn into expressing his or her understanding or interpretation of the topic at hand, which, in this instance, had to do with problem solving in process engineering. Also to note is the strong lead which the mediator provides and the way in which s/he keeps the interaction moving. In the following extracts, " $M$ " refers to the mediator and " $A$ ", " $B$ ", " $C$ " and " $D$ " to the participants in the group. To assist in following the interactions, the dialogue of the mediator is italicised.

M You mentioned "solution plan", what do you understand by a solution plan?

C A solution plan is ... (proceeds with her explanation).

M Mr A, would you like to add anything to what she said or explain it in a different way? 
A Um - (declined with a shy comment).

B Like, if you use the VICTOR method (interjects with a contribution).

M Ms D?

D Um ... ya ... it's, like, taking the problem and ... (Continues with her observation.)

The second extract illustrates how the mediator ensured that significant conceptual issues were not overlooked.

M One thing I didn't hear from any of you was the whole idea of connections - making connections. What do you understand by making connections?

B That from the given information you can ... (Proceeds with his explanation.)

M Mr A, what do connections mean to you?

A (Proceeds with his explanation.)

The third extract illustrates how the mediator prompts the students to review and clarify aspects of the discussion. Also to note is the technique of having students repeat or comment on what others in the group have said. Apart from the reinforcement and clarification which this provides, it helps to signal to students that they need to concentrate on following what others are saying in the discussion, and creates a common focus which the mediator sees as central to learning.

M OK, let's clarify what has been said. What did you say? Say it again.

C I have to ... (Continues with her response.)

M You said something about relevant. Relevant and irrelevant - what did you mean by that?

C (Answers the question.)

D But I don't think it's only about ... (Offers a different perspective.)

M Mr A, what has she said that's different from what was said before?

A She said she took ... (Continues with his answer.)

The next two sections outline how the MIG methodology was developed.

\section{THEORETICAL BACKGROUND}

In the literature on the mediation of learning, three types of context are evident learner-mediator, learner-peer and learner-self. In the former context, socio-cultural theories of learning have been cited - in particular (Vygotsky 1978) - to explain how 


\section{THE SCHOLARSHIP OF TEACHING AND LEARNING IN HIGHER EDUCATION}

the interaction between a mediator and a learner facilitates more extensive learning than would occur if the learner learned alone (Goos et al. 2002). The mediator interprets the articulations of the learners and, on this basis, can prompt or nudge the learner towards different associations of thought and a shift in their thinking (Feverstein \& Feverstein 1991; Vygotsky 1978). Feverstein, in particular, has elaborated on what mediators need to do in order to facilitate this shift (see Table 4.1). In addition, he argues that when a mediator is effective in facilitating a shift in the reasoning, understanding or thinking of learners in regard to the specifics of a particular learning context, a transformation can also occur in their general level of cognitive functioning (Feuerstein 1979; Feuerstein \& Feuerstein 1991).

Usually, when Vygotsky's ideas are invoked, the mediator is seen as a 'more competent other' such as a teacher, parent or more senior peer. However, Vygotsky also noted that learning could be enhanced in learner-peer contexts even in the absence of the more-competent-other. According to his theory, enhancement could potentially occur in groups consisting of peers of similar expertise even though that expertise may be limited - each peer "possessing some knowledge and skill but requiring the others' contribution in order to make progress" (Goos et al. 2002:195). Other dynamics have been reported to explain the enhancement of learning brought about by students articulating their thinking in peer group settings. Goos et al. (2002) noted "mutual adjustment and appropriation of ideas rather than a simple transfer of information and skills" (p. 195). Mahalingam, Schaefer and Morlino (2008) describe how verbal interactions facilitate the identification and correction of misconceptions. Enhanced learning can also result from improved metacognition brought about by the articulation of ideas in a group setting (Giles 2006). An example is that of becoming more aware of the efficacy of logical thinking in problem solving as opposed to attempting to learn by simply reading a chapter and trying to memorise its content (Mahalingam et al. 2008).

Even in the absence of interaction with a peer or a more-competent-other, the act of articulation itself has been shown to enhance learning. VanLehn and Jones (1993) and Chi, De Leeuw, Chiu \& Lavancher (1994) have studied this 'self-explanation effect' where improved learning occurs as students explain to themselves the texts they are reading or the examples they are working through. VanLehn and Jones found that the primary dynamic that seems to be at play here is 'gap-filling' - a process whereby the act of self-explanation uncovers knowledge gaps in the evolving understanding of a student and thereby prompts internal clarification to fill those gaps.

While the enhancement of learning in the ways just described is clearly supported in the literature, there are also reports of instances where such enhancement did not 
occur. The articulation of student thinking in group interactions appears to benefit the average to above average student and seems to be most effective when participation in the group discussions is active and evenly distributed among students (LindblomYlanne, Pihlajamaki \& Kotkas 2003). However, Benckert and Pettersson (2008) report that the benefit is not as evident for students who have too little knowledge compared to others in the group, or when group dynamics are poor, or when student motivation is low (Dolmans, Wolfhagen, Scherpbier \& Van der Vleuten 2003). In the latter case, not only is effective learning diminished but the facilitator's task of mediating learning is made relatively more difficult.

\section{THE DEVELOPMENT OF THE MIG METHODOLOGY}

\section{Background}

The MIG methodology was developed in the context of the first-year programme for chemical and metallurgical engineering students at the University of the Witwatersrand, Johannesburg (Wits), South Africa. This context is typical of the difficult teaching and learning situations that occur in the first year of higher education in South Africa large diverse classes with the majority of students receiving instruction in a language other than their mother tongue, and a socio-political background and secondary educational system that has resulted in many students being under-prepared (Rollnick, Manyatsi \& Green 1997; Yeld 2003) for an engineering education programme that maintains the standards set by the Washington Accord (http://www.ieagreements. org/Washington-Accord). Attempts to address these difficulties and to transform university structures so that it was better prepared in serving the students it receives (Masenya 1995) have a long history at Wits (Pinto 2001; Woollacott, Henning \& Skuy 2003).

The specific context in which the MIG methodology was developed is that of an 'introduction to process engineering' course for first-year chemical and metallurgical engineering students. This course is one of four full-year technical courses the students take along with two half-year, non-technical courses. This course - termed 'Process' by the students - has the double mandate of introducing them to their engineering disciplines and of addressing developmental issues such as communication, and study and learning skills. Students find the course difficult and the pass rates are low and fluctuate from year to year between 55 and $70 \%$.

While the other first year courses maintain a fairly traditional format, the 'Process Course' has been progressively modified by the inclusion of active learning principles in an effort to enhance learning and student development. The traditional lecture-plus- 


\section{THE SCHOLARSHIP OF TEACHING AND LEARNING IN HIGHER EDUCATION}

tutorial approach had been adjusted to include a variety of active learning methods. At the time of the development of MIGs, about half of the allotted lecture hours were devoted to group-based, case-study work and active learning elements such as 'think-pair-share' and peer-assessment (Boud, Cohen \& Sampson 2001; Sivan 2000; Topping 1998), and 'muddy cards' (Hall, Waitz, Brodeur, Soderholm \& Nasr 2002) had become regular features of the course. Students were encouraged to form peer study groups outside class and the peer-problem-solving technique (Lochhead 2001) was explained and encouraged in the tutorial sessions and in these study groups.

\section{The problem}

In essence, the problem that prompted the development of the MIG format was that too many students in the Process Course were performing poorly and were struggling to grasp the more complex engineering concepts. In 2006, the low quality of answers to some test questions and 'fuzzy thinking' by some students in discussions during tutorials suggested that the conceptualisation of the concepts was slow and error prone for many of the students, particularly the academically weaker ones. In addition, the length of time it took many students to 'get into a problem' during tutorials and case studies suggested that their grasp of concepts, their interpretation of word problems and/or their problem-solving abilities were inadequate.

What was particularly concerning was that this disappointing performance came about despite the considerable effort put into improving students' academic performance by implementing principles of good teaching practice such as formative and continuous assessment, use of active learning methodologies, regular feedback to and from students, and reasonable tutorial and tutoring structures. I was aware that there were several possible reasons for the academic underperformance noted: the execution of the teaching innovations mentioned was sometimes less than optimal and, to some extent, limited resources constrained our efforts - for example, in the extent of the training our tutors received.

An analysis of what could be done to improve the quality of student learning suggested that the overall structure of the Process Course was appropriate though improvements in the execution of some of its elements could be made. These will not be discussed here. Class surveys showed that the students appreciated and responded positively to the active learning features of the course and so an additional measure of this kind aimed at improving the students' conceptualisation of key concepts was considered appropriate. 


\section{Design principles}

The following principles guided the design of the additional active learning measure that was first implemented. They also guided the development of the subsequent prototypes which evolved into the MIG format.

- The intervention needed to complement the existing curriculum design both structurally - it needed to fit in - and conceptually - it needed to be aligned to the intended learning outcomes, course content, assessment procedures, and learning environment (Biggs 2003).

- The teaching and learning activity to be deployed should accelerate student learning through a process of dialogical interactions that would require students to articulate their understanding of concepts and of the thinking associated with those concepts. The theoretical basis behind this idea was outlined earlier.

- The interventions should be implemented as part of the existing tutorial system and would run in parallel to normal tutorial work.

- The intervention should be strongly mediated for theoretical, practical and contextual reasons.

- The theoretical reason was that there is a relationship between the quality of mediation and the quality of student learning and development (Feverstein \& Feverstein 1991; Mehl 1991; Shur, Skuy, Zietsman \& Fridjhon 2002; Vygotsky 1978) so that the extent of enhancement of learning is likely to be greater the greater the quality of mediation.

- The practical reason for strong mediation had to do with the efficient use of available time: strong mediation was more likely to lead to time efficiency than weak mediation. Time efficiency was an issue because the interventions were to run in the tutorial sessions without taking up too much of the time allocated for tutorials.

- The contextual reason was that, in my experience teaching the Process Course, few students were strong mediators and, all too often, the peer discussions that did arise from time to time were very time consuming and frequently did not reach a satisfactory resolution. The quality of mediation skills was uneven even with the post graduate students who were already involved as tutors. Accordingly, it was not considered viable to expect strong mediation from either peers or post graduate tutors. It was decided, therefore, that the additional measure should be some form of group discussion strongly mediated by an academic member of staff or experienced engineer. (Subsequently, some post graduates were trained successfully as MIG mediators.)

- The new measure should be made available to all students and not just 'at-risk' students who were struggling conceptually. Here the reasons were ethical and practical. Ethically, the targeting of one group of students for special treatment was considered to be problematic because it would 'label' some students as requiring 


\section{THE SCHOLARSHIP OF TEACHING AND LEARNING IN HIGHER EDUCATION}

'special treatment' and would exclude non-at-risk students from a measure which could be beneficial to them. There are also practical difficulties with identifying accurately which students are at-risk and which are not. (This principle was not always observed in the early trials when the methodology was still experimental.)

A principle which emerged later in the development of the MIG format concerned the composition of the groups. In the theoretical background presented earlier, it was noted that students with different knowledge and ability reacted differently to active learning environments which involved group discussions. According to the literature, measures to enhance learning through group discussions were likely to be less effective with 'weaker students' and also with students whose knowledge was significantly less than that of others in a group. In general, experience in the early MIG trials supported this. Accordingly, the decision was taken to make the groups fairly homogeneous so that group discussions could be orientated to the level and abilities of the students in each group.

\section{Iterative development of the MIG format}

\section{First Prototype}

Late in 2006, some initial trials were undertaken to 'get a feel' for how these mediated interactions could be implemented. The class was split into tutorial groups of about thirty students each supervised by an academic with help from one or two postgraduate tutors. During the course of the afternoon tutorial the academic chaired a discussion on a pre-selected topic - often an example from a test the students had done the previous week. The trial consisted of ten sessions. There was no formal evaluation of their effectiveness but informal feedback from both teaching staff and the students indicated that the activity was considered to be worthwhile but that it needed to be better structured. It was also very clear that the group size was too large: too many students remained passive in the discussion. In addition, it was observed that the academic staff members too easily drifted into a teaching mode rather than a mediation mode.

\section{Second Prototype}

In 2007, further trials were carried out with smaller group sizes and a less formal structure. The first objective of these trials was to learn how best to make the interactions more dialogical and to promote student articulation of their conceptions. To this end, I did all the mediation myself. The second objective was to experiment with the size of the group to see how this affected the interactional dynamics in the group. 
The groups were formed in an ad hoc manner during several of the afternoon tutorial sessions. Students were selected randomly from those present at the tutorial. Sometimes students were asked which topics they wanted to discuss. At other times the topics were pre-selected from concepts or issues which the students were known to be struggling with. Again, no formal assessment was made about the effectiveness of the sessions. Rather, tentative conclusions were reached from personal reflection on how effective the interactions seemed to have been. It was quite apparent that as the size of the group decreased there was a general improvement in the quality of interaction and the degree of student engagement. In addition, it was found that with the initial group size of 12 to 15 some students inevitably could not participate meaningfully in the interactions in the time available. The same was true when the size was reduced to six to eight. Only when the size was reduced to four students did the interactions gain an ambiance, momentum and shared participation that seemed optimal.

\section{Third Prototype}

Once a group size of four had been settled upon, a further trial was implemented in the second half of 2007 to evaluate more carefully the effectiveness of the methodology. The groups were formed in the same ad hoc manner as in the previous trial and, again, I mediated all of the sessions. Various kinds of data were collected for the evaluation: observations by a colleague who was an educational psychologist; audio recordings of the sessions; and a student survey at the end of the trial. In addition, an opportunity presented itself to conduct a controlled experiment. The findings from all of this data are discussed in the next section.

During this trial, two unexpected incidents occurred. The first was a criticism by the educational psychologist about how I was mediating the sessions. She indicated that I tended to lapse into a teaching mode and that my mediation knowledge and skills needed improvement. Accordingly, the initial sessions of the trial concentrated on improving my mediation skills through coaching and feedback by her.

The second incident had a major impact on the format and structure of the interaction groups. This happened as a consequence of the small size of the groups and the fact that I was the only mediator and a maximum of three consecutive sessions were conducted in any one tutorial session. This meant that only 12 out of the 100 students present were being selected to participate in the trial sessions. The sessions had become so popular that students not selected began to ask if they could sit in and observe. This was a significant development and lead to the MIG structure described earlier: four participants with a larger group of observers. Not only did it become a regular 


\section{THE SCHOLARSHIP OF TEACHING AND LEARNING IN HIGHER EDUCATION}

feature of the groups, but it increased the effective group size and so considerably eased the logistical problem created by insisting on a MIG format that included only four students participating in a discussion. Initially, the number of observers per session was small (four to eight) but, when time pressures or other problems arose, as many as 25 observers were invited to attend. The optimum number of observers for a MIG interaction was the subject of later investigation.

\section{Full implementation (Prototypes 4, 5 and 6)}

The results of the evaluations conducted in the third trial were very encouraging (see next section) and it was decided to implement the MIG intervention for the entire class of 2008. Because this coincided with a large increase in student numbers, the implementation was only conducted in the second semester of 2008. Two post graduates were trained as mediators, undergoing the same kind of coaching I had received from my educational psychologist colleague. The class was split into groups of 20 to 25 students based on the mid-year exam results so that groups were fairly homogeneous with regard to academic ability. Multiple, parallel sessions were provided weekly. A class survey was conducted at the end of the year to assess the students' experience. The results of this are also discussed in the next section.

In 2009, a similar full implementation was conducted but for the full academic year. There were two modifications to the MIG structure in this implementation. Firstly, the MIG sessions were no longer run as part of the tutorial session. This avoided the disruption in the tutorials that occurred every time students left for or returned from a MIG session. It also signalled to the students that the MIG sessions were a separate, important and integral part of the course structure.

The second modification was the group size. This was made as small as practically possible under the constraints that every student in a large class would have a MIG session weekly. However, it was found that the size - around 13 - was too small because a real and negative sense of depletion set in if just two or three students were absent. This problem did not reoccur in 2010 when the size was increased to around 15.

\section{THE EVALUATION OF THE MIG METHODOLOGY}

In this section, I present the findings of the analyses conducted on the data from the 2007 student survey returns and the controlled experiment. The purpose of the studies was to gain insight into how students experienced the MIG sessions, what dynamics were operating in the sessions and their impact on student learning. Four studies are presented. Studies 1 and 2 analysed respectively the nature and distribution of the 
students' experience, Study 3 the impact of observing compared to participating in a MIG session, and Study 4 the results of the control experiment.

\section{Study 1: Analysis of the survey of the students' experiences of MIG sessions}

\section{Data collection}

To gather data from as many students as possible class surveys were conducted in 2007 and 2008. In 2007, the survey was conducted towards the end of the academic year during the period when the MIG methodology had been 'on trial'. The questionnaire took students about 20 minutes to complete. The response rate was 70\% of the class of 112: 22 of the respondents had been participants only, 15 observers only, 15 participants and observers, and 26 had not attended any MIG sessions. All together 52 students - about half the class - had experienced at least one session and also had completed a questionnaire.

In 2008, MIG sessions had been implemented for all students as a weekly component of the course. The class survey was much less detailed than the 2007 survey and again was conducted towards the end of the academic year. It asked students to "tell me about what you think about each of the following". The MIG component of the course was only one of five items in the list following the question. Of the 157 students in the class, 118 responded - a 75\% response rate. In both surveys, absenteeism during the tutorial sessions when the surveys were administered was the primary reason for the response rates not being closer to $100 \%$.

\section{The student surveys}

To ensure that students were constrained as little as possible in how they responded to the survey, the questions were open ended: restricted response questions were used sparingly and only when very specific information was sought - such as recommendations about the frequency of MIG sessions.

The 2007 class survey explored the students' experience and perceptions of the MIG sessions in some detail. The questionnaire began with very general questions (such as "what are your general thoughts and feelings about MIGs"), moved to more specific ones (such as "what do you think is the purpose of MIGs") and then to very direct questions about key issues. The latter were framed both negatively (such as "describe any difficulties you experienced") and positively (such as asking students to describe "any benefits you noticed in your learning" or in "your grasp of concepts"). The questions were sequenced in this way in order to minimise the possibility that answers to the more specific questions might influence students responses to the more general questions. With some questions, students were prompted to think about specific 


\section{THE SCHOLARSHIP OF TEACHING AND LEARNING IN HIGHER EDUCATION}

issues, for example difficulties with language, or being 'on the spot' as a participant with the consequential affective pressure, or how being a participant compared with being an observer.

\section{Data analysis}

The 2007 survey returns were analysed using the methodology of thematic content analysis. This is a well-established methodology that ensures a systematic and replicable identification and description of the content of a set of texts and from this identifies the themes that exist in that content (Janesick 1994; Krippendorf 1980). Increasingly, qualitative research of this kind has been shown to produce rich detail and insight that is not forthcoming from quantitative investigations (Cohen, Manion \& Morrison 2007; Sherman \& Webb 1988).

The objective of the analysis was to reduce the volume of the data and to establish as objectively as possible the essential content of what students had communicated in their survey returns. The analysis proceeded as follows. Each student survey return was coded using the emergent coding approach described by Weber (1990). This involved analysing the content of each return and coding words, phrases and sometimes sentences which expressed single definable ideas or experiences which students were communicating. The codes emerged as the returns were read and analysed, the same code being used for responses or experiences that were very similar. Returns were re-read and analysed in this way by two readers until the point of 'theoretical saturation' when no more types of responses were emerging (Krippendorf 1980). Similar codes were then collapsed into categories - sub-themes - that were mutually exclusive and exhaustive. Where appropriate, sub-themes that were related were grouped together into larger categories - themes. Finally, the themes and subthemes were labelled appropriately. The analysis of the 2008 returns was conducted in a similar way.

\section{Results}

Table 4.2 classifies the essential content of the student responses in 2007 under four headings: (1) Reactions to MIG sessions; (2) Comments about conceptual growth and development; (3) Perceptions about learning benefits and outcomes from MIG sessions; and (4) Comments about participating in MIGs compared to observing in MIGs. The students' reactions, comments and perceptions relating to the first three of these categories are explained and elaborated in detail after the table. The fourth category of responses - comparing observing and participating - is analysed in Study 3. 
TABLE 4.2 Classification of the content of the student responses

\begin{tabular}{|c|c|c|}
\hline 1. Reactions to MIG sessions & $\begin{array}{l}\text { 2. Comments about } \\
\text { conceptual growth and } \\
\text { development }\end{array}$ & $\begin{array}{l}\text { 3. Perceptions about } \\
\text { learning benefits and } \\
\text { outcomes from MIG sessions }\end{array}$ \\
\hline $\begin{array}{l}\text { 1.1 Reactions to MIGs as an } \\
\text { educational innovation } \\
\text { 1.2 Affective reactions to MIGs } \\
\text { - Discomfort and } \\
\text { disengagement } \\
\text { - Positive affective reactions } \\
\text { 1.3 Reactions related to } \\
\text { students' language constraints } \\
\text { - They caused difficulties for } \\
\text { participants in MIG sessions } \\
\text { - MIGs facilitated language } \\
\text { attainment } \\
\text { 1.4 Reactions related to } \\
\text { students' constraints in technical } \\
\text { discourse } \\
\text { - They caused difficulties for } \\
\text { participants in MIG sessions } \\
\text { - MIGs facilitated discourse } \\
\text { attainment }\end{array}$ & $\begin{array}{l}\text { 2.1 MIGs promoted concept } \\
\text { formation and understanding } \\
\text { 2.2 MIGs developed thinking } \\
\text { and problem-solving skills } \\
\text { 2.3 MIGs developed reflective } \\
\text { practice } \\
\text { 2.4 Skills gained through MIGs } \\
\text { transferred to other subjects }\end{array}$ & $\begin{array}{l}\text { 3.1 Perceptions about the } \\
\text { educational outcomes of MIGs } \\
\text { 3.2 Perceptions about how } \\
\text { MIGs facilitated learning } \\
\text { - Broadens perspective } \\
\text { - Perspective broadened by } \\
\text { peer contributions } \\
\text { - Exposes misconceptions } \\
\text { - Forces concentration } \\
\text { - Provides individual attention } \\
\text { - Forces self-explanation } \\
\text { 3.3 Perceptions about personal } \\
\text { gains }\end{array}$ \\
\hline
\end{tabular}

\section{Student reactions to the MIG sessions}

\section{Reactions to MIGs as an educational innovation}

There were positive, ambivalent and negative reactions to MIGs as an educational innovation. Positive reactions were evident in statements such as the MIG sessions were "helpful", "relevant", "must be continued", "not enough of them" and "[appreciate the] interaction with the lecturer". The language here is clearly that of endorsement and appreciation of the MIG format. Most students made comments of this kind. Ambivalent reactions to the sessions were expressed in terms of uncertainty such as "not sure how it works". Negative reactions were conveyed by statements such as "a waste of a tut period" and "exposes how stupid you are". Although the ambivalent and negative reactions reflect only a minority of student experiences they are important to note as they suggest that, for some students, careful planning and support may be necessary to prepare them more adequately for MIG participation. 


\section{THE SCHOLARSHIP OF TEACHING AND LEARNING IN HIGHER EDUCATION}

\section{Affective reactions to MIG sessions}

Here the student statements conveyed emotion-related reactions to MIG sessions. Negative affective responses were reported as discomfort caused by the MIG sessions and were associated with some degree of disengagement at a personal level. The language of the students here is typified by words and phrases such as "do not like them", "scared", "nervous", "exposes how stupid you are", and "don't have the confidence - was afraid". Such expressions suggest that preparation and support for anxious students must be available to ensure that such students do not become alienated during the MIG sessions.

In contrast, a substantial number of students clearly found the MIG sessions to be a positive affective experience. Examples of statements demonstrating this are "enjoyed them" and "was cool and fun". Some statements conveyed a mixed reaction such as "started out disliking it ended up liking it", and "only observing was comfortable".

\section{Language- and discourse-related reactions}

Some student statements had to do with difficulties related to language or technical discourse. In regard to the former, responses reported difficulties derived from having English as a second language and difficulties associated with communicating in the English domain at a tertiary level. Examples are: "difficult to explain myself", "difficulty [sic] to put thoughts into words", and "get stuck when trying to explain problems". For many students the language experience in the interactional format of the MIG sessions had been a rewarding and enriching one. Here statements focused on how MIG sessions facilitated language attainment as indicated by quotes such as "practice talking in English", "developed my vocabulary", "learn how to pronounce words" and "gives me the language".

The technical language and discourse in the Process Course is new and difficult for some students as indicated by statements such as "my vocabulary is pathetic", "pronunciation of words is pathetic". As with statements about language constraints, there were also students who saw the MIG sessions as a useful vehicle for addressing such difficulties. This is demonstrated by statements such as "gets me to use the correct terms", and, again, "gives me the language".

\section{Student experiences relating to conceptual growth and development}

\section{MIGs promoted concept formation and understanding}

Statements exemplifying this, include "now [I] understand concepts", "refine concepts", "understand concepts at a deeper level", "correct misconceptions", "give concepts clarity", "fill gaps", "connect concepts". This was a dominant theme in the returns and 
gives much credence to the endorsement given to the MIG initiative by the majority of the students. This subcategory is closely linked to the next.

\section{MIGs developed thinking and problem solving skills}

Examples of statements in this category are "can now think more deeply", "thinking through helps with problems", "I now give precise explanations". A nuance behind these comments is that, because of the MIG experience, students had shifted in regard to the way they think about and approach an educational task.

\section{MIGs developed reflective practice, and skills gained through MIGs transferred to other subjects}

Statements in these categories are considered together because they are related and because both were discernible in only a few of the survey returns. Relevant examples of statements in the former category are "realise that you don't understand when you thought that you did" and "I [now] know what type of questions to ask when studying". Such statements suggest that the MIG sessions had helped some students to recognise the importance of reflection in their thinking and studying. Other statements suggest that enhancements in reflective or other skills gained through MIG sessions were beginning to work across the curriculum into other subjects. Evidence of this is demonstrated by comments such as "can understand concept[s] in other subjects", "have made me study better and I've applied it in my other courses", and "my grasping of important concepts has improved not only in Process but in other subjects as well".

\section{Student perceptions about learning benefits and outcomes from MIG sessions}

Here the student responses looked beyond the issue of conceptual growth and development that characterises the previous category: they focused on the learning benefits or outcomes perceived to result from attending MIG sessions and on the perceived educational processes leading to these benefits or outcomes. These perceptions differ from the comments in the previous category in that student statements relate more to what the MIG format achieved as opposed to what individuals had gained.

\section{Perceptions about the educational outcomes of MIGs}

Here statements conveyed perceptions about educational outcomes other than conceptual growth and development. Examples include "promote group skills", "reinforce what is taught in class", "promote peer learning" and "fill gaps". There were also a few ambivalent comments such as "don't see how it is helpful". 


\section{THE SCHOLARSHIP OF TEACHING AND LEARNING IN HIGHER EDUCATION}

\section{Perceptions about how MIGs facilitated learning}

Several returns included statements about specific features of the MIG sessions that some respondents had noted as facilitating learning. These statements constitute student-supplied reasons for the educationally positive experiences they had reported. The following six processes were evident.

\section{Broadens perspective}

Statements illustrating this are: "fuller explanations", "fills gaps", and "look at concepts from different perspectives".

\section{Perspective broadened by peer contributions}

Statements in this category are similar to those in the previous one, except that the "broadening of perspective" reported is directly linked to hearing what peers or the mediator said in the sessions. Examples are "seeing how the mistakes one's fellow students make are rectified which are sometimes the same mistakes I make", "get to know how other students think and how they develop a way to solve a given problem", "see how others answer questions", and "allow[s] you to share ideas and confirm with everybody else".

\section{Exposes misconceptions}

Examples of statements in this category are: "exposes superficial understanding", "helps see ... where you have misconceptions", and "corrects misconceptions".

\section{Forces concentration}

Student statements here focused on how the MIG sessions asked "hard questions" and "force[d] you to think" and to "think for ... [your]self".

\section{Provides individual attention}

Here students noted, for example, that a MIG session "helped understand[ing] ... because it got to the root of our problems individually" and "attend[ed] to individual problems".

\section{Promotes learning through self-explanation}

The act of explanation or discussion was noted by some students as helping to promote learning. Illustrative examples are: "I found that I didn't clearly understand until asked to explain", and "when we are doing the discussion we are really forced to think".

\section{Perceptions about personal gains}

This category groups student statements that reported personal gains derived from having attended MIG sessions. The overwhelming majority of them were very positive 
and constituted high endorsement of the MIG sessions as the following examples indicate: "my marks have improved", "coped better", "I have more in-depth understanding", "[l] process questions more quickly", "find tut questions more easy", "[l] work more accurately", and "improved the way I study". A handful of students indicated ambivalence about the benefits of the MIG sessions with comments such as "[personal improvements attained were] not dramatic", and "can't say much".

\section{Discussion: The qualitative findings from the survey study}

The intention of the survey studies was to investigate how students had experienced the MIG format and to gain insight into the educational dynamics operating in MIG sessions and how these impacted student learning and the students' experience. Two themes stand out from what students were communicating in the survey returns educational processes and outcomes and individual change. Students noticed and reported on a variety of educational processes operating in the MIG sessions. Some offered evaluations of MIGs as an educational innovation, some made observations about its structure and some reported specific educational processes they found effective or beneficial. The latter - listed in Table 4.2 - are of particular interest because they can be compared to processes which the literature suggests could be, and perhaps should be, operating in the kind of learning environment which MIGs provided.

Students noted processes which, according to Vygotsky, should be evident when a 'more competent other' mediates learning: expanding the awareness of the learner, concentrating attention, exposing and correcting misconceptions, and interacting with the learner to stretch the range of his or her learning. Students also noted mechanisms which theory and research suggest should occur in peer mediation and self-mediation: 'gap filling', the self-explanation effect, mutual adjustment of perceptions, exposure of misconceptions, and peer contributions facilitating progress in learning.

It is clear from the survey returns that not only were these processes operating but that they facilitated learning - students changed, or so they reported. Most students reported changing in ways intended by the MIG design - their conceptual understanding improved. However, as is evident from Table 4.2, change was also reported in regard to cognitive and reflective skills, improvements in technical discourse and language usage, and changes that helped students to cope better or to work more quickly and effectively. What the returns tell us is that students experienced a novel innovation in which the educational processes deployed changed them in a variety of ways as summarised in Table 4.2. 


\section{THE SCHOLARSHIP OF TEACHING AND LEARNING IN HIGHER EDUCATION}

The content analysis of the survey returns highlighted a third theme - interactions which relates to the interactional dimensions of the processes operating in the MIG sessions. In some cases, the students' affective responses to these interactions were positive and motivational. In other cases, they were not: the MIG context placed language, discourse and affective demands on the students and difficulties arose when these demands were too big a stretch. To some degree and for some students, such interactional difficulties appear to have diminished the educational impact of the MIG sessions. The prevalence of these negative reactions to the MIG sessions is one of the topics taken up in the next study.

\section{Study 2: Quantitative indications from the class surveys: The distribution of student experiences of MIG sessions}

The qualitative study just described painted a rich picture of the dynamics operating in the MIG sessions and also gave a general indication that the students reacted positively to and endorsed the MIG methodology. However, it also showed that a minority of the students were less positive: their reasons were primarily affective and language-related in nature. The short study presented in this section had the objective of clarifying the relative extent of positive and negative reactions to the MIG sessions or, more accurately, to establish the proportion of the students who experienced or responded to the MIG sessions in different ways that could be defined unambiguously. It was a quantitative study that addressed the question of how the students experienced and responded to MIG sessions.

\section{Design and execution of the study}

There were two sources of data for this study. The first was the restricted-answer questions in the 2007 survey - those which required students to select their answers from a limited range of options. There were two such questions. The rationale behind the first - "How frequently would you like to attend MIG sessions?" - was to get an indirect indication of the extent to which the students rated the MIG sessions positively. It would be expected that students who appreciated or saw value in the MIGs would recommend a high frequency, while those who did not appreciate them would not want to attend them at all or very infrequently.

The second restricted answer question probed the students' affective reactions to the MIGs and how this impacted on their motivation to participate in them. The question was preceded by a preamble that summarised the kind of affective pressure participants in a MIG session might feel and possible reasons for them. It read, "you are somewhat exposed to others and you are face to face with your lecturer. You have 
to explain yourself and this might be difficult for you. If you make mistakes everyone sees. Your proficiency with English is on show."

Students were then asked, "To what extent were you comfortable with this as a participant - or, if you have only observed, to what extent would you be comfortable with this?" The students were then asked to select from options that constituted different combinations of affective reaction and motivation to participate in MIG sessions. The options are listed along with the results in Table 4.3.

TABLE 4.3 Responses to restricted answer questions in the 2007 survey

\begin{tabular}{|c|c|c|}
\hline QUESTION & $\begin{array}{l}\text { Number of } \\
\text { responses }\end{array}$ & Response categories \\
\hline $\begin{array}{l}\text { How frequently } \\
\text { would you like } \\
\text { to attend MIG } \\
\text { sessions? } \\
\text { (52 responses) }\end{array}$ & $\begin{aligned} & 2(4 \%) \\
5 & (10 \%) \\
& 4(8 \%) \\
16 & (31 \%) \\
24 & (46 \%) \\
1 & (2 \%)\end{aligned}$ & $\begin{array}{l}\text { Never. } \\
\text { Once per quarter. } \\
\text { Once per month. } \\
\text { Once per week. } \\
\text { As often as possible. } \\
\quad \text { (Once per week or as often as possible =77\%) } \\
\text { Not sure. }\end{array}$ \\
\hline $\begin{array}{l}\text { To what extent } \\
\text { were you or } \\
\text { would you be } \\
\text { comfortable to be } \\
\text { a participant in a } \\
\text { MIG session? } \\
\text { (46 responses) }\end{array}$ & $\begin{array}{l}24(52 \%) \\
17(37 \%) \\
3(7 \%) \\
1(2 \%) \\
0 \\
1(2 \%)\end{array}$ & $\begin{array}{l}\text { No problem. } \\
\text { Was/would be a bit uncomfortable but that's OK. } \\
\text { (No problem or a bit uncomfortable but that's OK=89\%) } \\
\text { Was/would be uncomfortable quite a lot but that's OK. } \\
\text { Was/would be uncomfortable - not sure I want to do it. } \\
\text { Definitely uncomfortable and don't want to do it. } \\
\text { I have another reaction which is ... }\end{array}$ \\
\hline
\end{tabular}

The second source of data used in Study 2 was the proportion of the students who reacted to, experienced or perceived the MIGs in the ways described by the categories in Table 4.2 (Study 1). The data was generated by re-examining the coded survey returns and doing a simple head count of the number of students who made statements falling in each category. During the analysis it became evident that the number of categories could be usefully reduced to five essentially different types of reaction to the MIG sessions. These five 'reaction types' are listed and described in Table 4.4 along with the proportion of students who reported each type of reaction.

The 2008 survey returns were examined in a similar manner and the results are also included in Table 4.4. However, it should be noted that the 2008 questionnaire did not specifically solicit information about language and affective issues: it simply asked students to "tell me about what you think about each of the following" of which MIGs was one of five items. 


\section{THE SCHOLARSHIP OF TEACHING AND LEARNING IN HIGHER EDUCATION}

TABLE 4.4 Distribution of student perceptions and experiences of MIGs

\begin{tabular}{|c|c|c|c|}
\hline \multirow{2}{*}{$\begin{array}{l}\text { TYPE OF } \\
\text { REACTION }\end{array}$} & \multirow{2}{*}{$\begin{array}{l}\text { Perception or experience of the student } \\
\text { (Derived from the } 2007 \text { survey only. } \\
2008 \text { responses were categorised primarily } \\
\text { on the basis of the left-hand column.) }\end{array}$} & \multicolumn{2}{|c|}{$\begin{array}{l}\text { Proportion of students } \\
\% \text { (number) }\end{array}$} \\
\hline & & $\begin{array}{l}2007 \text { Survey } \\
\text { (52 returns) }\end{array}$ & $\begin{array}{l}2008 \text { Survey } \\
\text { (178 returns*) }\end{array}$ \\
\hline $\begin{array}{l}\text { Positive } \\
\text { experience }\end{array}$ & $\begin{array}{l}\text { Student reported positive personal change plus } \\
\text { perceived positive educational processes in MIGs } \\
\text { and/or positive educational outcomes from them. }\end{array}$ & $\begin{array}{c}92 \% \\
\text { (48 students) }\end{array}$ & $\begin{array}{c}87 \% \\
\text { (103 students) }\end{array}$ \\
\hline $\begin{array}{l}\text { Experience } \\
\text { not } \\
\text { positive }\end{array}$ & $\begin{array}{l}\text { Student was ambivalent or negative about MIGs } \\
\text { and was negative or ambivalent about personal } \\
\text { change resulting from attending them. }\end{array}$ & $\begin{array}{c}8 \% \\
\text { (4 students) }\end{array}$ & $\begin{array}{c}1 \% \\
\text { (1 student) }\end{array}$ \\
\hline $\begin{array}{l}\text { Outcomes } \\
\text { dubious }\end{array}$ & $\begin{array}{l}\text { Student was ambivalent or negative about } \\
\text { beneficial outcomes from MIGs and/or whether the } \\
\text { educational processes in MIGs were beneficial. }\end{array}$ & $\begin{array}{c}12 \% \\
\text { (6 students) }\end{array}$ & $\begin{array}{c}7 \% \\
\text { (8 students) }\end{array}$ \\
\hline $\begin{array}{l}\text { Discourse } \\
\text { difficulties }\end{array}$ & $\begin{array}{l}\text { Student experienced difficulties in MIGs because of } \\
\text { language or discourse constraints. }\end{array}$ & $\begin{array}{c}13 \% \\
\text { (7 students) }\end{array}$ & $0 \%$ \\
\hline $\begin{array}{l}\text { Affective } \\
\text { difficulties }\end{array}$ & $\begin{array}{l}\text { Student experienced affective difficulties in MIGs } \\
\text { with some discomfort in the sessions. }\end{array}$ & $\begin{array}{c}35 \% \\
\text { (18 students) }\end{array}$ & $\begin{array}{c}3 \% \\
\text { (4 students) }\end{array}$ \\
\hline
\end{tabular}

\section{Analysis and discussion: The quantitative findings from the class surveys}

It is quite clear from the 2007 and 2008 surveys that the reactions of most students to the MIG sessions were overwhelmingly positive. Table 4.4 shows that $92 \%$ of the students surveyed in 2007 had had a 'positive experience' and justified the positive rating they gave MIGs on the basis of a variety of personal learning gains that the students perceived were forthcoming. In 2008, 87\% reported a positive experience. Table 4.3 conveys a similar degree of endorsement. In the first place, $77 \%$ of students stated they would like to attend MIG sessions weekly or as often as possible. Secondly, even students who had been uncomfortable as a participant (or felt they might be) saw value in the sessions and were willing to attend them: $89 \%$ of students reported either no affective discomfort or that the discomfort they had felt or might feel was not an issue significant enough to impair their motivation to attend MIG sessions.

In some cases, the positive reactions to MIG sessions were very enthusiastic, as the following quotations indicate.

"I always had a shallow understanding of concepts and relied on text books and my study group for assistance. But the sessions have been incredibly helpful in such an extent that I [now] always ask myself questions whenever studying a concept." 
"These are the most help and efficient exercise in all my courses. They should be implemented in the other courses."

"Very, very, very, very helpful! Most of the deep understanding of the concepts comes from the [MIGs]."

"This for me is the cream for all my problem-solving and understanding place of the week."

"This is the best thing that helps me with [the course]. I don't think I was going [sic] to manage to pass [the course] without [these] groups."

"The best." "Brilliant!" "Very productive."

While a positive experience of a methodology is not, on its own, sufficient reason for recommending that methodology, it is not inconsequential. Students are likely to gain more from an intervention if they appreciate it and value what it appears to offer them.

As Table 4.4 indicates, there were four types of reactions to MIGs that were other than positive. The first of these was a generally negative reaction: students were ambivalent or negative about the MIG sessions and the outcomes derived from them. In $2007,8 \%$ of students reported this reaction, but in 2008 only $1 \%$ did so.

With regard to the other three types of non-positive reaction - outcomes dubious, discourse difficulties, and affective difficulties - Table 4.5 provides additional information that gives an indication of the extent to which these reactions did or did not impact negatively on the benefits students saw or experienced in the MIG sessions. The table shows that all students who experienced 'discourse difficulties' (as defined in Table 4.4) also reported a positive experience. It also indicates that all but one of the students who seemed to be dubious about outcomes did seem to derive some benefit from the MIG sessions. A similar conclusion seems to apply to students who experienced affective difficulties in the MIG sessions: three quarters of them also reported positive outcomes and/or positive personal change and only a quarter also reported a negative reaction to MIG sessions. 
THE SCHOLARSHIP OF TEACHING AND LEARNING IN HIGHER EDUCATION

TABLE 4.5 Impact of non-positive reactions on perceived benefits of MIGs

\begin{tabular}{|c|c|c|c|c|}
\hline \multirow{3}{*}{$\begin{array}{l}\text { TYPE OF } \\
\text { REACTION }\end{array}$} & \multirow{3}{*}{$\begin{array}{l}\text { Perception or experience } \\
\text { of the student }\end{array}$} & \multicolumn{3}{|c|}{$\begin{array}{c}\text { Proportion of students } \\
\% \text { (number) }\end{array}$} \\
\hline & & \multirow{2}{*}{$\begin{array}{l}2007 \text { Survey } \\
\text { (52 returns) }\end{array}$} & \multicolumn{2}{|c|}{ Also reported. } \\
\hline & & & $\begin{array}{c}\text { 'Positive } \\
\text { experience' * }\end{array}$ & $\begin{array}{l}\text { 'Experience } \\
\text { not positive' * }\end{array}$ \\
\hline $\begin{array}{l}\text { Outcomes } \\
\text { dubious }\end{array}$ & $\begin{array}{l}\text { Student was ambivalent or negative } \\
\text { about beneficial outcomes } \\
\text { from MIGs and/or whether the } \\
\text { educational processes in MIGs } \\
\text { were beneficial. }\end{array}$ & $\begin{array}{c}12 \% \\
\text { (6 students) }\end{array}$ & $\begin{array}{c}10 \% \\
\text { (5 students) }\end{array}$ & $\begin{array}{c}1 \% \\
\text { (1 student) }\end{array}$ \\
\hline $\begin{array}{l}\text { Discourse } \\
\text { difficulties }\end{array}$ & $\begin{array}{l}\text { Student experienced difficulties } \\
\text { in MIGs because of language or } \\
\text { discourse constraints. }\end{array}$ & $\begin{array}{c}13 \% \\
\text { (7 students) }\end{array}$ & $\begin{array}{c}13 \% \\
\text { (7 students) }\end{array}$ & $0 \%$ \\
\hline $\begin{array}{l}\text { Affective } \\
\text { difficulties }\end{array}$ & $\begin{array}{l}\text { Student experienced affective } \\
\text { difficulties in MIGs with some } \\
\text { discomfort in the sessions. }\end{array}$ & $\begin{array}{c}35 \% \\
\text { (18 students) }\end{array}$ & $\begin{array}{c}27 \% \\
\text { (14 students) }\end{array}$ & $\begin{array}{c}8 \% \\
\text { (4 students) }\end{array}$ \\
\hline
\end{tabular}

These results are an important complement to the earlier findings that an overwhelming majority of students endorsed the MIG methodology. It indicates that even when students experienced affective and language-related difficulties in MIG sessions most also derived discernible benefit from attending them. This conclusion is supported by the earlier finding that affective difficulties did not appear to impair the motivation of student to attend MIGs. It is further supported when note is taken of an important difference between the results from the surveys in 2007 and 2008 shown in Table 4.4. It seems that, when not specifically asked about language and affective difficulties, few students commented on them: in 2008 no students reported language difficulties and only $3 \%$ commented on affective difficulties compared to the $35 \%$ in 2007 who were asked specifically about them.

\section{Study 3: The impact of a structural feature: 'Observing' vs 'Participating'}

As indicated earlier in the chapter, the inclusion of observers in MIG sessions was a response to requests from students and the recognition of logistical benefits - it increased the group size and consequently simplified the logistics associated with providing a small group activity to all students in a large class. The brief study reported in this section looked beyond the issue of organisational convenience to explore how the ostensibly passive activity of observing impacted student learning. More specifically, the study investigated the question of how the experience of observing in a MIG session compared with the experience of participating and the extent to which it impacted student learning differently. 
The data for the study derives from two questions in the 2007 survey: students were asked how participating (as opposed to observing) had been beneficial to them and how observing (as opposed to participating) had been beneficial. The findings are summarised in Figure 4.2. They show that the majority of students (53\% of respondents) saw benefits in both participating and observing. Where students did express a preference either way it was towards observing and not towards participating. That students saw value in observing in MIG sessions is further attested to by their requests early in the development of the format to 'sit in' on the MIG sessions.

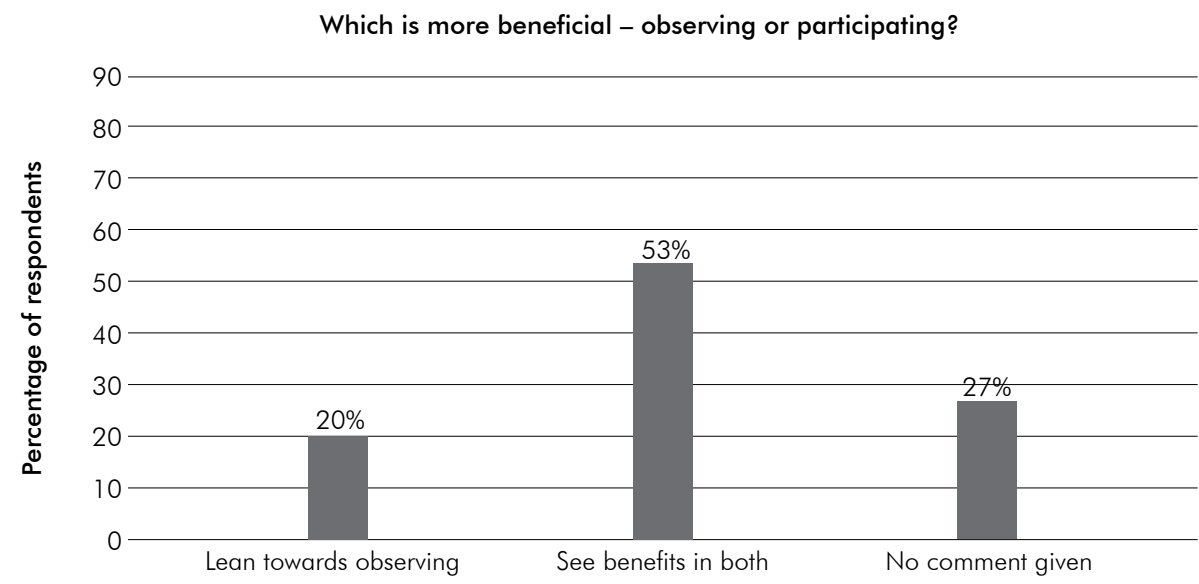

FIGURE 4.2 The relative merits of observing vs. participating

Extracts from students' responses indicate a variety of reasons why they found observing in a MIG session to be worthwhile. Some examples of these are as follows.

"Seeing the way the lecturer is rectifying the mistakes that my fellow students make (which are sometimes the same mistakes as the ones I make) [...] has helped me with understanding the actuality of the concepts."

"Observing is getting more information as to how others understand the material, [...] you don't get to share how you understand the material but get how others understand it."

"As to learning, I feel that the sessions benefit you more as a participant if you ask questions, while as an observer much more, in that you take notes and listen to everyone's opinion without feeling the tension [that is associated with being a participant]."

"You don't worry about [having] to answer when it is your turn to explain so you can fully concentrate on the explanation and clarifications."

The most significant implication of these findings is that observers appeared to be cognitively engaged in the MIG discussions. This is in accord with literature which 


\section{THE SCHOLARSHIP OF TEACHING AND LEARNING IN HIGHER EDUCATION}

reports that being silent in group discussions does not necessarily mean a lack of cognitive engagement or mental passivity. For example, Moust et al. (1987) reports the phenomenon where students may not be participating verbally in a group discussion but nevertheless are 'covertly elaborating' to themselves the substance of the discussion. Remedios, Clarke and Hawthorne (2008) report similar findings in their study of 'silent participants' in PBL settings and cite related work by Graham (1996) on self-verbalisation. They also cite an interesting study by Blue, Stratton, Nash and Schwartz (1998) which found no correlation between the extent of a student's verbal engagement in PBL activities and their performance in the examinations that assessed the quality of learning in those activities: silent participants appeared to learn about as well as those who were more verbally engaged in the group discussions.

With regard to the nature of the learning processes experienced by observers in a MIG sessions, more research is needed. The indications from the survey study are that most of the learning processes are the same for participants and observers. Where there are differences they appear to revolve around the implications of observers not being involved in asking or answer questions. Negatively, observers in the study were not able to benefit from asking their own questions. Positively, they could "concentrate fully on the explanations and clarifications", did not "feel the tension" associated with being a participant, and, if they wished, could concentrate on making notes.

\section{Study 4: A Quantitative evaluation of the impact of MIGs on student learning: A controlled experiment}

This study addressed the question of the extent to which learning outcomes are different when the teaching and learning environment includes MIG sessions. It involved a tightly controlled experiment that compared the performance of an experimental group against that of a control group. It was easy to set up such an experiment when the MIG format was still 'on trial' in 2007. At the time, ad hoc MIG groups were formed during the two afternoon tutorial sessions each week, which meant that each week some students participated in MIG sessions but many did not. Accordingly, it was possible to set up a study in which the experimental group consisted of students who had participated in a MIG session on a given topic and a control group of those who had not attended any MIG session devoted to that topic.

\section{Experimental design}

For the investigation, the topic selected for discussion in the MIG sessions was one that, in previous years, students had found to be particularly troublesome. All students in the class were 'taught' the topic using the same format as in previous years - a double lecture followed by an afternoon tutorial session. MIG groups were 
constituted in an ad hoc manner by taking students out of the tutorial session into an adjacent venue for a short MIG session - about half an hour. After the MIG session, the students returned to the tutorial venue. This arrangement enabled a total of five MIG sessions to be devoted to the topic in question during the two tutorials that followed the relevant lecture. Uniformity of mediation in these sessions was assured in that I mediated each personally. The MIG participants in these sessions constituted the experimental group with those who did not attend any of the five MIG sessions constituting the control group. Students in both groups had the same length of formal exposure to the topic: the only difference was a period of half an hour when the experimental group were in MIG sessions while the control group simply continued with the tutorial session.

An unplanned twist in the circumstances of the study increased the force of the comparison between the two groups. This twist was a consequence of the tendency for MIG groups to self-select during the trial period. As shown in Table 4.6, the students in the experimental group turned out to be academically weaker than those in the control group. ('Academic strength' was gauged after the investigation on the basis of psychometric data - specifically their scores from the Ravens Advanced Progressive Matrices (RAPM) (Raven, Raven \& Court 1998) which had been gathered at the beginning of the academic year. Categories were based on the students' RAPM scores as follows: Strong: 28-33; Average: 22-27; Weak: <22). As the table shows, the difference is quite stark: $11 \%$ of the experimental group was 'academically strong' and $39 \%$ 'academically weak' as compared to the control group where $37 \%$ were 'academically strong' and only 16\% 'academically weak'.

The research question for the study was whether participation in a MIG session improved conceptualisation of the troublesome concept. To assess the conceptual grasp which the students had developed of that concept, results from a term test three weeks after the tutorial and MIG sessions were evaluated. The test assessed, among other things, the topic at the centre of the controlled experiment. To keep the evaluation of the results as tight as possible, mastery of the concept was gauged simply by whether or not students applied it correctly when answering the relevant test question. Experience from previous years and the counter-intuitive nature of the concept meant that if the student had not understood the troublesome concept properly they were most unlikely to apply it correctly.

\section{Results}

Table 4.6 shows the results of the investigation. The proportion of students who applied the concept correctly was $89 \%$ for the experimental group and $71 \%$ for the control group - a difference of $18 \%$. From an educational perspective this difference 


\section{THE SCHOLARSHIP OF TEACHING AND LEARNING IN HIGHER EDUCATION}

is quite dramatic suggesting that the MIGs had indeed improved the conceptual grasp of the students who had attended the sessions. However, from a statistical perspective, the difference does not reach levels of significance: a Chi-Squared Test on the data gave a p-value of 0.121 and the Fisher Exact Test (which is better suited to the analysis of situations involving small subsample sizes) gave a value of 0.203 .

TABLE 4.6 Indications of student mastery of the troublesome concept $(p=0.203, n=69)$

\begin{tabular}{|l|c|c|c|c|c|c|c|c|}
\hline \multicolumn{4}{c|}{ Level of academic ability* } & $\begin{array}{c}\text { Number } \\
\text { of } \\
\text { students }\end{array}$ & \multicolumn{2}{c}{$\begin{array}{c}\text { Applied the concept } \\
\text { correctly? }\end{array}$} \\
\cline { 2 - 9 } & Strong & Average & Weak & Yes & $\%$ Yes \\
\hline Experimental group & $11 \%$ & $50 \%$ & $39 \%$ & 18 & 2 & 16 & $89 \%$ \\
\hline Control group & $37 \%$ & $47 \%$ & $16 \%$ & 51 & 15 & 36 & $71 \%$ \\
\hline
\end{tabular}

* Categories of academic ability were based on the students' scores from the Ravens Advanced Progressive Matrices (RAPM) (Raven, Raven \& Court 1998) as follows:

- Strong: RAPM scores of 28-33; - Average: RAPM scores of 22-27; - Weak: RAPM scores <22.

\section{Discussion}

It is not unusual in educational research of this nature to obtain interesting results that do not reach levels of statistical significance. For example, the classic phenomenographic work of Marton and Sälï (1976) did not attempt a statistical analysis to support their seminal claim that the adoption of a deep approach to learning is associated with better learning outcomes than that which accrues from the adoption of a surface approach to learning.

Despite the lack of statistical confirmation, we conclude that the large difference in performance between the two groups provides strong evidence that the MIG sessions improved the conceptual grasp of the students in regard to the topic in question. The reason for reaching this conclusion is that there was a major difference in the academic ability of the two groups. This statement requires a little elaboration.

The RAPM scores for the category of 'strong academic level' in Table 4.6 correspond to superior intellectual capability: these are students who should all graduate in regulation time possibly with distinction. At the other end of the scale, the category 'weak academic level' is associated with RAPM scores that fall below 22, which corresponds roughly to a fairly well recognised cut-off level for acceptance into engineering degrees (Skuy, Rushton \& Seabi 2002). It implies that these students are very much at risk of failure and some should probably not have been admitted into the degree programme. On the basis of these differences and the relative distribution of 'strong' and 'weak' students delineated in Table 4.6, it would be expected that the performance of the control group would far outstrip that of the experimental group. 
The reverse happened. This is remarkable enough in itself but the extent of the reversal makes it doubly remarkable: any educationist would be very pleased if an intervention produced an improvement of $18 \%$ in test performance with students of similar academic ability. That it achieved an improvement of this magnitude with students of significantly weaker academic ability is nothing less than dramatic. This suggests that the MIG sessions enabled an impressive level of intellectual engagement and conceptual grasp that was all the more impressive because the improvement was achieved with only one relatively short intervention - a 30- to 40-minute MIG session.

A further ramification of this result is worth noting. In the literature review, mention was made of findings that appear to imply that the kind of mediation which the MIG methodology aims to facilitate may not benefit academically 'weaker' students to the extent that they benefit the average and above-average students (Benckert \& Pettersson 2008; Lindblom-Ylanne et al. 2003). This intimation is not consistent with our findings: the academically weakest students in the class clearly did derive much benefit from the educational processes operating in the MIG sessions.

Two qualifications apply to the findings just presented. Firstly, the small number of students in the controlled experiment precluded a meaningful statistical examination of the effect of the relative academic strengths of the two groups. Secondly, the improvement in academic performance at the heart of the analysis applied to only one topic among many: this singular focus of the controlled experiment enabled a very tight assessment of student learning, but it left unanswered the larger question of how MIG sessions affected the overall pass rate and academic performance of the students. The development of the MIG methodology coincided with dramatic increases in class size (from 112 in 2007, to 157 in 2008, to 260 in 2009 and to 280 in 2010) and in the educational background of entrants (changes in the national secondary education systems meant that entrants in 2007 and 2008 had experienced a different kind of secondary education from entrants in 2009 and 2010). It was considered that these changes were very likely to have had an influence that would make pass rates unreliable indicators of any longitudinal impact which MIG may have had on student throughput.

\section{Implications of the findings from the evaluation studies}

The purpose of the evaluation studies was to gain insight into the dynamics operating in MIG sessions and to investigation how these influenced student learning. The qualitative study based on student survey returns showed that the educational processes in the MIG sessions were very much in line with those which theory and research indicate should be expected in the kind of learning environment the MIG 


\section{THE SCHOLARSHIP OF TEACHING AND LEARNING IN HIGHER EDUCATION}

format was designed to provide. The level of agreement between theory and what students reported seeing in the MIG sessions has two significant implications.

The first is that it provides evidence of the reliability of the findings of the survey study. That first-year engineering students, unversed and uninstructed in the educational processes associated with mediated interactions, reported observing a range of features that line up so well with the literature is noteworthy. It gives credence to the claim that what they reported was actually what they had seen and experienced and not some invention or ideas about what should happen in the sessions. In effect, it gave 'observational validity' to the findings in that what students communicated in the survey returns reliably conveyed what they had observed and experienced. It should be noted that the findings also had content validity in that they faithfully reflected the content of what students had written in the returns. This is claimed on the grounds that the study had adhered to a well-established research methodology, namely content analysis.

The second significant implication of the agreement between theory and what students reported is that the MIG methodology can and did create a learning environment in which educational processes potentially beneficial to student learning were operating. Study 3 suggested that beneficial learning processes were operating for observers as well as for participants in the MIG sessions.

With regard to whether these processes did achieve the learning benefits which theory and research suggest should be forthcoming, both the qualitative and quantitative studies yielded positive findings. In the first place, the content analysis of the 2007 student survey showed that the educational processes operating in the MIG sessions seem to have been powerful in changing students: individual change was a dominant theme in what the students communicated. About 90\% of those surveyed in 2007 reported personal change that ranged from enhanced conceptualisation to cognitive and meta-cognitive development, to improvements in language usage, technical discourse and learning practices. Linked to these changes were reports of changes in academic performance: improved speed, accuracy and execution in problem solving, coping better, and, in some cases, improved grades. In 2008, a similar proportion of students reported personal changes of these kinds. While no claim is made that every student changed in all the ways listed, it is significant that almost all of these students reported some change - especially improved conceptual understanding - and most reported beneficial change in more than one area.

Additional interesting conclusions from the survey study relate to the type and range of the changes reported. The objective of the MIG sessions was to enhance conceptual mastery by having students articulate and discuss key conceptual issues 
in the course content. However, the learning environment set up to facilitate such articulation seemed to have had a much more multidimensional impact on learning. This is reminiscent of Feverstein's point that a deeper level transformation in cognitive functioning can occur when a learner wrestles with the cognitive particularities of specific situations in a strongly mediated environment (Feverstein 1979; Feverstein \& Feuerstein 1991). It can be concluded from these observations that the MIG sessions in 2007 and 2008 implemented an interactional learning environment which generated multiple learning impacts leading to, according to student reports, a rich variety of benefits for student learning.

It is one thing to have processes in place that have the potential to benefit learning. It is another for students to believe that their learning has benefited from those processes. But whether, objectively, MIGs facilitated an actual improvement in learning is another matter altogether. It is at this point that the findings from the quantitative study become particularly relevant.

In that study, participation in a half hour MIG session resulted in an experimental group of academically weaker students outperforming by a margin of $18 \%$ a control group of academically stronger students who had not participated in the relevant MIG sessions. Unfortunately, the margin of difference did not reach the $25 \%$ needed to be able to claim statistical significance: on the grounds of statistics alone, it cannot be claimed that the performance of the two groups was significantly different. However, when the 18\% difference in test performance is examined in the light of both statistical and other information together, a different picture emerges.

What the statistical analysis showed is that there was an $80 \%$ probability that the $18 \%$ margin of difference was not the result of random variation. The fact that the students in the experimental group were 'weaker' academically than those in the control group suggests that the probability is actually higher than this. It can be argued strongly that this probability must be higher still when account is taken of the qualitative findings. First, the MIG sessions did immerse students in an environment in which many effective learning processes were operating. Second, students reported very convincingly that real learning benefits were forthcoming from the MIG sessions they attended. Taking all these factors into consideration provides strong evidence that the MIG sessions did lead to a marked improvement in the performance of the students in the experimental group and that the MIG methodology is able to bring about a very real improvement in student learning.

A note of caution accompanies this positive conclusion: the interactional nature of the MIG format was a stretch for some students. Difficulties with the language of instruction, shyness, lack of self-confidence, and possibly even socio-cultural issues 


\section{THE SCHOLARSHIP OF TEACHING AND LEARNING IN HIGHER EDUCATION}

created affective and language-related difficulties that can inhibit the benefits a student might gain from MIG sessions. However, the findings suggest that the impact of such difficulties can be minimised if the MIG sessions are conducted according to the following guidelines:

- The mediator must be sensitive to language and affective difficulties, be alert to the early signs of their emergence, and skilled in dealing with them if they occur.

- Students should be inducted carefully into the MIG methodology.

- The sessions should be frequent and regular so that students build familiarity and confidence with the format.

- The MIG groups should be fairly homogeneous in nature particularly with regard to academic ability. When this is difficult to organise because students are new entrants and are not well known, the groups should be reformed as soon as possible after an induction period so that they are relatively homogeneous.

- MIG groups should be relatively small in size: a number between 15 and 18 seems optimal.

The findings of the survey study suggest that when the MIG methodology becomes a regular feature of the teaching and learning environment and the guidelines given here are adhered to, the number of students who experience affective and languagerelated difficulties and consequently do not benefit from engaging in MIG sessions is reduced to a very small proportion of a class.

\section{THE TRANSFORMATION POTENTIAL OF SCHOLARSHIP IN TEACHING: SOME REFLECTIONS AND CONCLUSIONS}

Kreber (2002) has presented a perspective on SoTL that distinguishes between excellence in teaching, teaching expertise, and scholarship in teaching. She concurs that the traditional measures of scholarship - the generation of new knowledge and its dissemination through peer-reviewed publications - can be applied to teaching but also suggests that "perhaps the most relevant educational knowledge is created ... neither through experience nor publications alone but through the struggle with the mediation of theory and practice" (p. 16). In this concluding section of the article, I will use the MIG development described above as reference data for reflecting on the various issues which Kreber raises and on the transformative potential of SoTL.

In overview, most of the issues mentioned by Kreber are evident in the development of the MIG methodology. The development is an example of an educational practitioner conducting research and development work in order to address an educational problem that has arisen in the specifics of his or her teaching work. 
Serious engagement with any problem of this kind is what would be expected of 'excellence in teaching'. Engagement with the relevant literature and conducting research to obtain data relevant to the resolution of the problem would be an expected manifestation of 'teaching expertise'. Conducting such research according to accepted standards would be an expectation of 'scholarship in teaching' as would appropriate dissemination of the new knowledge generated by that research. While the MIG development has been disseminated in various ways (discussed shortly), it is the issue of 'the struggle to integrate theory and practice' that is perhaps the most interesting feature of the work from the point of view of scholarship. Does the example of the MIG development in any way validate Kreber's suggestion that a struggle at the coal face of teaching can, under appropriate conditions, be considered scholarly? If so, how and what might those conditions be? What kind of new knowledge can be generated from such a struggle? In what way does such knowledge have 'transformative potential'? Are there distinctive features of this kind of research that should be recognised and given appropriate credit when thinking about SoTL?

In addressing such questions it is interesting to reflect on how the development of the MIG methodology evolved and the kind of research that was conducted. Because it emerged from the particularities of practice, there was no initial intention to develop and disseminate a new pedagogy or develop or test theory. There was no formal 'statement of the problem' or 'research question' followed by the formal implementation of a research methodology to answer that question. Rather, what transpired was an exercise in reflective practice leading to a developmental process: a problem was noticed; a possible cause was identified; a possible intervention was thought out and then implemented. The developmental process that followed was iterative in nature not because that was the initial intention but because reflection on the strengths and shortcomings of the current state of the intervention suggested possible improvements which were then implemented and the ensuing effects reflected upon again. Only retrospectively were the iterations thought of as prototypes and the whole process recognised as a loose form of developmental action research. Only when the developmental process reached a point where more objective evaluations became necessary were methodologies used that were more rigorous in nature than acting on the outcomes of practitioner reflection.

In addition to the methodological progression just described, other 'progressions' were operating during the MIG development. The awareness that what was being developed might have wider relevance grew as the development progressed. Dissemination of the findings of the work was increasingly more actively pursued first 


\section{THE SCHOLARSHIP OF TEACHING AND LEARNING IN HIGHER EDUCATION}

informally with colleagues and then more formally both at the local level (university teaching and learning seminars) and at a global level (a research report, this article and a paper submitted for publication). In parallel and as a consequence of these progressions, there was an increasing degree of engagement with relevant literature.

How then does the development and experience just described relate to SoTL and to its transformative potential? The first point to make is that new knowledge - a new pedagogy - was produced. The pedagogy has a solid theoretical framework, has been tested and found effective in a given context, and there has been some dissemination of the work to the appropriate community of practice. From this perspective, it seems that there has been scholarship at work.

The second point to make is that the genesis of new knowledge from within the context of practice - what we might call 'in-practice-scholarship' (or, in Kreber's terms, "expertise in teaching") - is somewhat different in nature to the generation of new knowledge by means of a more traditional research format. I would argue that scholarship can potentially be exercised at every point in the kind of development work that has been described. For example, even before any 'in-practice' research and development work has begun, scholarship can be operating: the sharpness of the identification of a problem can be enhanced if the practitioner's emersion in relevant literature, theory and good practice has been scholarly. The same can be said for the identification of possible causes of the problem, and for the conception and implementation of potentially effective interventions. Even if the consequential development of an intervention follows similar lines to the MIG development (implementing iterative modifications based on the insights of reflective practice and judgement) a scholarly background and disposition can enhance the sharpness and effectiveness of the perception, reflection and judgment needed. In addition, scholarly insight can sharpen the awareness of the potential relevance of findings in the development process and even of wider relevance of the intervention itself. Finally, when the developmental process requires rigorous research methodologies, analysis and subsequent dissemination, processes are required that fall squarely in the domain of scholarship.

The third point to make is that the genesis of new knowledge from, as it were, 'the depths of practice' is both valuable and important. I would argue that there are kinds of new educational knowledge that can be acquired no other way. For example, it is unlikely that the features that are peculiar to the MIG methodology - in particular, its mix of active interaction and apparently passive attentive listening - would have emerged except as the result of being shaped by practice and contextual peculiarities. If certain kinds of new knowledge can emerge only from the coalface of practice, 
then the kind of scholarship that is associated with the emergence of such knowledge should be appropriately recognised.

When it comes to the transformative potential of such scholarship, the outcomes of the MIG development speak for themselves - a new pedagogy, a significant shift in a first-year curriculum accompanied by a significant impact on student learning. In addition, the experience coming out of involvement in this kind of scholarship has been personally transformative: a deeper appreciation of the transformative power of in-practice research and development; a deeper awareness and appreciation of how the activities of scholarship - academic and research rigour and interaction with the literature and the community of higher education - can be powerful in advancing the effectiveness of curricula, teaching practice and, consequentially, the quality and depth of student learning.

Further, and in conclusion, the transformative potential of the new knowledge that has emerged from this type of scholarship is evident when its potential impact on educational practice is considered. Firstly, knowledge about the dynamics and potential impact of structured and guided discussion groups has been reinforced, augmented and, in some ways, advanced by the specific findings coming out of the development: specific evidence has been found that the learning dynamics which theory predicts should occur in such group activity did in fact occur and led to consequential individual change in a range of areas - conceptual change and improvements in conceptual understanding, in thinking and meta-cognitive skills, in learning practices, and in technical discourse. Secondly, a new pedagogy has been developed that can be placed alongside related pedagogies in ways that can expand the number of nuances that can be contemplated in the way these pedagogies might be implemented. Not to be underestimated is the potential impact on practitioners: if my personal experience in the MIG development is anything to go by, the engagement in and application of a deeper level of scholarship in the specific context of your everyday work can transform the way you view what you do, the way you engage with your students, the way you deliver your courses, and the way you engage with the larger issues of educational research, curriculum development and educational delivery more generally.

\section{ACKNOWLEDGEMENTS}

The work reported in this article was made possible by a grant from the South African National Research Foundation (NRF). I also acknowledge with thanks the helpful comments made by Prof Jeff Froyd on early drafts of the article. 


\section{THE SCHOLARSHIP OF TEACHING AND LEARNING IN HIGHER EDUCATION}

\section{REFERENCES}

Benckert S \& Pettersson S. 2008. Learning physics in small group discussions - Three examples. Eurasia Journal of Mathematics, Science and Technology Education, 4(2):121-134.

Biggs J. 2003. Teaching for quality learning at university. Second Edition. Buckingham: Open University Press/Society for Research into Higher Education.

Blue A, Stratton T, Nash P \& Schwartz R. 1998. Students communication apprehension and its effect on PBL performance. Medical Teacher, 20(3):217-221.

Boud D, Cohen R \& Sampson J (eds.). 2001. Peer learning in higher education: Learning from and with each other. London: Kogan Page.

Chi MT, De Leeuw N, Chiu M \& Lavancher C. 1994. Eliciting self-explanations improves understanding. Cognitive Science, 18(3):439-477.

Cohen L, Manion L \& Morrison K. 2007. Research methods in education. Sixth edition. London: Routledge/Falmer.

Dolmans DH, Wolfhagen HA, Scherpbier AJ \& Van der Vleuten CP. 2003. Development of an instrument to evaluate the effectiveness of teachers in guiding small groups. Higher Education, 46:431-446.

Feverstein R. 1979. The dynamic assessment of retarded performers: The Learning potential assessment device, theory, instruments and techniques. Baltimore, MD: University Park Press.

Feverstein R \& Feverstein S. 1991. Mediated learning experience: A theoretical review. In: R Feuerstein, PS Klein \& AJ Tannenbaum. Mediated learning experience (MLE): Theoretical, psychosocial and learning implications. London: Freund. 3-52.

Giles RM. 2006. Teachers' and students' verbal behaviours during cooperative and smallgroup learning. British Journal of Educational Psychology, 76:271-287.

Goos M, Galbraith P \& Renshaw P. 2002. Socially mediated metacognition: creating collaborative zones of proximal development in small group problem solving. Educational Studies in Mathematics, 49:193-223.

Graham C. 1996. Conceptual learning process in physical therapy students. Physical Therapy, 76(1):58-62.

Hall SR, Waitz I, Brodeur DR, Soderholm DH \& Nasr R. 2002. Adoption of active learning in a lecture-based engineering class. Paper presented at the 32nd ASEE/IEEE Frontiers in Education Conference, Boston, MA.

Janesick VJ. 1994. The dance of qualitative research design: Metaphor, methodology and meaning. In: NK Denzin \& YS Lincoln (eds.). Handbook of qualitative research. Thousand Oaks, CA: Sage. 209-219.

Kreber C. 2002. Teaching excellence, teaching expertise, and the scholarship of teaching. Innovative Higher Education, 27(1):5-23.

Krippendorf K. 1980. Content analysis: An introduction to a methodology. Beverley Hills, CA: Sage.

Laing D. 2007. Nurturing discussion in the classroom. In: K Smith (ed.). Teaching, learning, assessing: A guide for effective teaching at college and university. Oakville, Ontario, Canada: Mosaic Press. 58-77. 
Lindblom-Ylanne S, Pihlajamaki H \& Kotkas T. 2003. What makes a student group successful? Student-student and student-teacher interaction in a problem-based learning environment. Learning Environments Research, 6(1):59-76.

Lochhead J. 2001. Thinkback: A user's guide to minding the mind. Mahwah, NJ: Lawrence Erlbaum Associates.

Mahalingam M, Schaefer M \& Morlino E. 2008. Promoting student learning through group problem-solving in general chemistry recitations. Journal of Chemical Education, 85(11):1577-1581.

Marton F \& Säliö R. 1976. On qualitative differences in learning - I: Outcome and process. British Journal of Educational Psychology, 46:4-11.

Masenya DI. 1995. Reconceptualizing the academic discourse: Underprepared students or institutions or both? Academic Development, 1 (2):99-105.

Mehl MC. 1991. Mediated learning experience at university level: A case study. In: R Feuerstein, PS Klein \& AJ Tannenbaum (eds.). Mediated learning experience (MLE): Theoretical, psychological, learning implications. London: Freund. 157-178.

Moust JHC, Schmidt HG, De Volder ML, Belien JJ \& De Grave WS. 1987. Effects of verbal participation in small group discussion. In: JTE Richardson, MW Eysenenck \& DW Piper (eds.). Student learning. Research in education and psychology. Milton Keynes: Open University Press. 147-154.

Pinto D (ed.). 2001. Directory of science, engineering and technology foundation programs. Johannesburg: University of the Witwatersrand, College of Science, Central Printing Unit.

Raven J, Raven JC \& Court JH. 1998. The ravens advanced progressive matrices (RAPM). Oxford: Oxford Psychologists Press.

Remedios L, Clarke D \& Hawthorne L. 2008. The silent participant in small group collaborative learning contexts. Active Learning in Higher Education, 9(3):201-216.

Rollnick M, Manyatsi S \& Green G. 1997. Language, culture or disadvantage - What is at the heart of successful student adjustment to tertiary science courses? Paper presented at the Fifth Annual Meeting of the Southern African Association for Research in Mathematics and Science Education. University of the Witwatersrand, Johannesburg.

Seabi JM. 2004. Design, implementation and evaluation of a cognitive programme of first year engineering students. Unpublished PhD thesis. Johannesburg: University of the Witwatersrand.

Sherman R \& Webb R (eds.). 1988. Qualitative research in education. London: Falmer Press.

Shur Y, Skuy M, Zietsman A \& Fridjhon P. 2002. A thinking journey based on constructivism and mediated learning experience as a vehicle for teaching science to low functioning students and enhancing their cognitive skills. School Psychology International, 23(1):36-67.

Sivan A. 2000. The implementation of peer assessment: an action research approach. Assessment in education, 7(2): 193-213.

Skuy M, Rushton P \& Seabi JM. 2002. Background variables related to IQ test scores and university grades of first year African and non-African engineering students in South Africa. Paper presented at the Conference of the International Society for Intelligence Research, Nashville, TN. 


\section{THE SCHOLARSHIP OF TEACHING AND LEARNING IN HIGHER EDUCATION}

Topping K. 1998. Peer assessment between students in college and university. Review of Educational Research, 68(3):249-276.

VanLehn K \& Jones RM. 1993. What mediates the self explanation effect? Knowledge gaps, schemers or analogies? In: M Polson (ed.). Proceedings of the Fifteenth Annual Conference of the Cognitive Science Society. Hillsdale, NJ: Erlbaum. 1034-1039.

Vygotsky LS. 1978. Mind in society. Cambridge, MA: Harvard University Press.

Weber RP. 1990. Basic content analysis. Newbury Park, CA: Sage.

Woollacott LC, Henning L \& Skuy M. 2003. Addressing under-preparedness in entrants to the chemical engineering program at Wits. Paper presented at the South African Chemical Engineering Congress, Sun City, South Africa.

Xun G. 2004. A conceptual framework for scaffolding ill-structured problem-solving processes using question prompts and peer interactions. Educational Technology Research \& Development, 52(2):5-22.

Yeld N. 2003. Academic literacy and numeracy, in perspectives on entry threshold and enrolment systems. Pretoria: SAUVCA-CTP HE Admissions Project. 